\title{
What are bruises? Causes, Symptoms, Diagnosis, Treatment, Remedies
}

\author{
Aleksandr Urakov* \\ Leading Researcher, Professor, Dept. of Modeling and Synthesis of Technological Structures, Udmurt Federal Research Center of the Ural \\ Branch of the Russian Academy of Sciences, Izhevsk, Russia \\ *Corresponding Author: Aleksandr Urakov \\ Email: urakoval@live.ru
}

\begin{abstract}
Bruises are blood-stained areas of the skin that impair its aesthetic appearance. Bruises often occur in everyday life, when accidental falls, when hitting hard objects, when performing sports exercises and competitions, when performing medical procedures, and also often occur in the elderly and when using drugs that thin the blood. The skin in the area of bruises first has a reddish color, then successively acquires a blue, green and yellow color. Usually bruises persist for up to a week, and then go away on their own and without a trace. Bruising is not recognized by official medicine as an independent disease. Official medicine does not have medicines designed for urgent discoloration of the skin and the area of bruises. However, in recent years, drugs have been discovered that can discolor the skin in the area of bruises in a few minutes. This group of medicines was called oxygen-alkaline bleachers. Their main ingredients are Hydrogen peroxide and Sodium hydrocarbonate. The prescription of medicines is given.
\end{abstract}

Keywords: Bruise, Haematoma, Haemorrhage, Injury, Trauma, Damage, Hydrogen peroxide, Sodium hydrocarbonate, Oxygen-alkaline bleachers.

\section{Introduction}

The term "Bruise" comes from old English brȳsan, brīesan ("to bruise; crush"), from Proto-Germanic brausijaną, brūsijaną ("to break; crumble; crack"), Anglo-Norman bruiser, bruser ("to break, smash, shatter"), from Gaulish brus-, from Proto-Celtic bruseti ("to break"). Today it is already obvious that English term "bruise" is cognate with Scots term "brizz", German term "brausen" ("to roar; boom; pound"), Old English term "brosnian" ("to crumble, fall apart"), Dutch term "broos" ("brittle"), German term "brosame" ("crumb"), dialectal Norwegian term "brøysk" ("breakable"), Latin term "frustum" ("bit, scrap"), Old Church Slavonic term “бръснути” (brŭsnuti, “to rake”), and also Albanian term "breshër" ("hail").

Thus, it is clear that bruising was well known in the ancient world.

From ancient times until recently, it was considered indisputable that bruise, contusion, ecchymosis, and hematoma of tissues are almost the same phenomenon. ${ }^{2}$ It was believed that the most common cause of bruising is tissue trauma with a hard blunt object, which damages the capillaries. ${ }^{3}$ The matter is that most often bruises appeared in places of bruises in which victims felt soreness. In addition, symptoms of inflammation, such as local hyperemia, local hyperthermia, and swelling, often occurred at the site of the injury. All this was very similar to a normal local inflammation. The fact is that the bruise caused by the injury, is commonly swollen, and sometimes even painful for the first few days, but the pain usually goes away as the color fades. $^{2}$

Moreover, it is widely believed that a bruise is a common skin injury that results in a discoloration of the skin because the result of capillary damage is localized bleeding. As a result, some portion of the blood is extravasated into the surrounding interstitial tissues. Very often, bruises are not very deep under the skin, so that local bleeding causes a visible change in the skin color in the area of the injury. Then pigment from damaged blood cells deep beneath the skin collects near the surface of the skin, resulting in what we think of as a black and blue mark. ${ }^{2,3}$

It is established that initially, a fresh bruise may actually be reddish. It will then turn blue or dark purple within a few hours, then yellow or green after a few days as it heals. ${ }^{2}$ This discoloration leads to the classic "black and blue" appearance. When a bruise fades, it becomes green and brown as the body metabolizes the blood cells and bilirubin pigment in the skin. The bruise then remains visible until the remnants and traces of blood is either absorbed by tissues or cleared by immune system action. ${ }^{4}$

Until today, official medicine does not recognize bruises as a disease. Therefore, there are no special medications for treating bruises. At the same time, it is recognized that very often, bruises create a cosmetic problem. The fact is that since the bloody staining of the skin in the area of the bruise worsens the aesthetic appearance of the skin for many days. The fact is that official cosmetology does not offer medications for urgent discoloration of the skin in the area of a bruise.

\section{Definition}

Bruises worsen the aesthetic appearance of the skin and create a cosmetic problem that is solved independently in a few days. In official medicine, there are no drugs that provide urgent discoloration of the skin in the area of a bruise. $^{1,2}$

\section{Triggers of Bruise}

In many people bruises seem to be triggered by external factors. ${ }^{1-4,6}$ Possible triggers include:

1. Trauma: These are the most common bruising triggers. When struck hard with a blunt object on the soft tissue 
some of blood vessels in the skin break down. Blood pours from them into the skin and colors it.

2. Injections (Tissue punctures with an injection needle): These are common bruising triggers. Injections of drug solutions into the skin, under the skin, in the muscle, in the vein, etc.

3. Hypertension and hypertensive crisis: These are common bruising triggers. An increase in the value of systemic blood pressure in hypertension and especially during a hypertensive crisis, some blood vessels can not withstand the high blood pressure inside them and break down. Blood pours from a ruptured blood vessel into neighboring tissues and colors them.

4. Complications of diseases: Hemophilia, cirrhosis of the liver, von Willebrand's disease, vasculitis, senile purpura, cancers affecting the blood and bone marrow, such as leukemia, hemorrhagic fever.

5. Complications of drug therapy: Bruising for no reason? It could be due to these medications: anticoagulants (such as Heparin, especially in injections under the skin, Warfarin, Rivaroxaban, Apixaban and Dabigatran), NSAID pain relievers and NSAIDs (nonsteroidal anti-inflammatory drugs) like Aspirin, Ibuprofen (Motrin, Advil) and Naproxen (Aleve), steroids and glucocorticoids, for example, Prednisone (Rayos), antidepressants, such as Citalopram (Celexa) and Fluoxetine (Prozac) and some antibiotics.

6. The bite of a Gyurza snake, Viper, etc.

7. Other factors: Lack of vitamin $\mathrm{C}$ and/or vitamin $\mathrm{K}$, old age, insect, and animal bites (domestic and wild), etc.

\section{Classification of bruises}

Since bruises are not yet recognized by official medicine as an independent disease, there is no official classification of bruises. However, bruises have long been recognized in forensic medicine as irrefutable evidence of trauma resulting from a blow to soft tissues with a hard blunt object. ${ }^{8}$ Therefore, the indirect classification of bruises was formed first in the field of forensic medicine.

However, an analysis of this classification shows that it is not a classification of bruises, but a classification of injuries. Blunt impact injuries generally can be classified into four categories: contusion, abrasion, laceration, and fracture. $^{9,10,11}$ In this regard, currently, the classification of bruises is usually associated with the classification of injuries by hazard to human health, as recognized in forensic medicine and law enforcement agencies. ${ }^{8}$ (Tabl. 1).

Table 1: Severity, Bruises can be scored on a scale from 05 to categorize the severity and danger of the injury.

\begin{tabular}{|c|c|c|}
\hline \multicolumn{3}{|c|}{ Bruise harm score } \\
\hline Harm score & Severity level & Notes \\
\hline 0 & Light bruise & No damage \\
\hline 1 & Mild bruise & Little damage \\
\hline 2 & Moderate bruise & Some damage \\
\hline 3 & Serious bruise & Dangerous \\
\hline 4 & $\begin{array}{c}\text { Extremely serious } \\
\text { bruise }\end{array}$ & Very dangerous \\
\hline
\end{tabular}

IP International Journal of Comprehensive and Advanced Pharmacology, January-March, 2020;5(1):1-5
In addition, the fallacy of this classification of bruises according to their degree of danger to human health today has irrefutable scientific evidence. ${ }^{12,13,14}$

First, it should be noted that in this classification we are not talking about true bruises, but about complex damage to soft tissues with simultaneous blood staining of the skin in the area of damage. In this case, the skin may be cut, torn, torn off, crushed, and stained with blood both on the outside and inside. Moreover, the blood can be in the form of spots on the skin, in the form of a hematoma inside the skin or under the skin, in the form of a hematoma under the nail plate, as well as in the form of a crust on the surface of the wound.

Second, blood that has spilled from a blood vessel into the skin and other nearby tissues is not poison. Therefore, our blood can not threaten our health not only with intradermal, subcutaneous, intramuscular, but also with intravascular injection. Therefore, the blood of a person can not threaten his life and health not only when applying his own blood to the skin, but also with intradermal, subcutaneous, intramuscular, as well as with intravascular injection of this blood.

Third, the blood of a person that has got into his skin, subcutaneous fat and other tissues after the rupture of blood vessels or after injecting his own blood into the skin or under the skin without traumatic damage to soft tissues does not have a local irritating effect. ${ }^{13,15,16}$

Fourth, it has been shown that high-quality solutions of drugs produced for intramuscular and intravenous injections are more dangerous to humans than their blood. Therefore, an infiltrate created in the human skin by injecting its own blood looks like a bruise, but without symptoms of local inflammation, and an infiltrate created in the human skin by injecting a high-quality drug in the medicinal form of "Solution for injection" does not look like a bruise, but often manifests symptoms of local inflammation. ${ }^{13,17,18}$

And, finally, fifthly, blood is not dangerous for drugs, but many drugs damage the shaped elements and blood plasma during local interaction, for example, when administered intravenously. ${ }^{19,20}$

Thus, human blood that changes the color of the skin in the area of the bruise does not have a local irritating effect and does not pose a threat to human life and health. From this it becomes clear why true bruises are not recognized as an independent disease: the fact is that the skin in the area of the true bruise does not have symptoms of inflammation.

This is surprising, but it has been proven that a bruise in its pure form, namely, a bruise obtained by injecting a person's venous blood into their skin is not accompanied by symptoms of inflammation. It turned out that the symptoms of local inflammation are detected in the area of bruises only when a true bruise is combined with mechanical damage to soft tissues, for example, when a club is struck or the skin is pinched. ${ }^{12,13}$ On the other hand, symptoms of local inflammation are detected when there is no bruise, and 
the skin is completely healthy, for example, when the additional lobe of the breast is inflamed. ${ }^{21}$

That is why there is no reason to classify bruises according to their danger to human life and health, since true bruises are safe.

At the same time, based on practice, we should agree that in real life, bruises may or may not have an important aesthetic significance.

In this regard, the classification of bruises can be formed primarily on their significance for the aesthetic result and on their combination with concomitant factors of local tissue damage that cause subsequent local inflammation. It follows that there are grounds to classify bruises by their localization on the human body and combination with mechanical or other soft tissue damage. In particular, bruising can be localized on different parts of the body that have different aesthetic significance for the appearance of people. On the other hand, bruising can be combined with local tissue inflammation caused by mechanical, physical, chemical, physical-chemical, biochemical or biological damage. In turn, local tissue inflammation in the area of the injury can be reversible and irreversible.

Classification of bruises by their localization (taking into account the role for the aesthetic result):

Bruising in parts of the body that play an important aesthetic role in everyday life:

1. Bruising under the eyes.

2. Bruising on the face.

3. Bruising on the neck.

4. Bruising on the hands.

5. Bruises on the legs.

Bruising in parts of the body that are hidden from prying eyes in normal human life:

1. Bruising under the hair of the head.

2. Bruising on the torso and buttocks.

\section{Classification of bruises by their type:}

1. True bruise.

2. Hematoma.

3. Ecchymosis

4. Bleeding, also known as a hemorrhage.

Classification of bruises by their combination with local tissue inflammation:

Inflammation was caused by the following mechanical damage:

1. Damage by puncturing the skin (the puncture splinter, the puncture needle, the puncture by the hook, puncture wire, etc.)

2. Damage by cutting the skin with a sharp object (knife, razor, scythe, glass shard, etc.)

3. Damage by compression of the skin

4. Gunshot wound

5. Damage by scratching of the skin (abrasion)

6. Damage by rubbing (calluses disease)
Inflammation was caused by the following physical damage:

1. High intravascular pressure and / or low external pressure

2. Hot burn

3. Frostbite

4. Electric burn

5. Sunburn

6. Radiation exposure

Inflammation was caused by the following chemical damage:

1. Chemical burn

2. Alcohol burn

3. Alkaline burn

Inflammation was caused by the following physicalchemical damage

1. hypoosmotic irritation

2. hyperosmotic irritation.

\section{Inflammation was caused by the following biochemical} damage

1. Local aseptic inflammation

2. Ischemic damage

3. Hypoxic damage

4. Calcium damage

5. Irritation caused by an irritant (including medication)

\section{Inflammation was caused by the following biological damage \\ 1. Infectious damage (damage caused by viruses, bacteria, fungi, protozoa, etc.) \\ 2. Local allergic inflammation}

These ideas explain why so far indications for the treatment of true bruises include only one thing - the need to improve the aesthetic condition of the area of the body where the bruises appeared. $^{22,23}$

Bruises often have an unsightly shape, sometimes they are combined with bruises, so they are accompanied by swelling, soreness and local hyperthermia. All this spoils the aesthetic result. It is generally recognized that bruises are mainly a cosmetic and temporary problem, since usually after 5 to 8 days, the bruises disappear on their own. ${ }^{24}$

It is no secret that the treatment of true bruises is mainly cosmetic improvement of the aesthetic condition of the body surface in the area of bruises. And, first of all, this applies to bruises located on open areas of the human body. Of these, the first place in its importance is occupied by bruises localized under the eyes and just on the face.

In recent years, infrared imaging has made it clear that true bruises do not become inflamed. ${ }^{13}$ Therefore, true bruises frighten victims not with soreness, but with a deterioration in the color of the skin or mucous membranes. Therefore, the treatment of true bruises will be correct only in cases when the result of treatment will quickly restore the natural color of the tissues in the area of the bruise. 


\section{Cosmetic medications that quickly discolor bruises}

In recent years have been discovered that drugs can quickly discolor skin and other tissues stained with blood and/or discolor the skin in the area of bruises. ${ }^{25}$ This group of medications is called "Bruises bleaches", "Blood bleaches", «Oxygen alkaline dental's cleaners» or "Oxygen-alkaline bleaching cleaners" for blood stains, teeth and/or ceramics. $^{26.27}$ In addition, an original technology was invented for using bleach to immediately discolor the skin and nail plate in the area of bruises and hematomas.

To discolor the skin in the bruise area, it is suggested to use a solution containing $0.01-0.03 \%$ hydrogen peroxide and $2-4 \%$ sodium hydrocarbonate. This solution should be injected into the skin by intradermal injection. In this case, the drug must be administered in such a volume that will ensure the creation of a "lemon crust" effect in the skin in the entire bruise area. To accelerate and enhance the effect, local hyperthermia at a temperature of $+42{ }^{\circ} \mathrm{C}$ is recommended. ${ }^{25}$

It is shown that bruise bleachers can quickly dissolve and bleach blood spots on the body and inside the human body due to alkaline saponification of plasma protein-lipid complexes, cold boiling inside the biological mass and oxidative discoloration of hemoglobin and its color metabolites. Cold boiling and oxidative discoloration occurs due to the formation of oxygen gas from hydrogen peroxide under the action of the catalase enzyme. ${ }^{25,26,27}$

\section{Author's conclusion}

Bruising is a common cause of deterioration of the aesthetic condition of the skin, mucous membranes and nails, and yet there is underestimated in cosmetology and pharmacology. It is shown that a person's own blood does not have a local irritating effect on their skin, so a true bruise is not accompanied by symptoms of inflammation. In this regard, there is no reason to consider the bruise a disease. And there is no reason to prescribe anti- inflammatory drugs.

The prevention of bruises consists in avoiding the trigger factors of blood vessel rupture, and the treatment of true bruises consists in the rapid discoloration of hemoglobin and its color metabolites in the skin thickness. Medicinal products that have proven their role in the discoloration of hemoglobin and its pigments include aqueous solutions of hydrogen peroxide and sodium bicarbonate.

To quickly discolor the skin in the bruise area, it is suggested to make an intradermal injection of a solution containing $0.01-0.03 \%$ hydrogen peroxide and $2-4 \%$ sodium hydrocarbonate. The solution entering such a volume that will create the effect of "lemon crust". Then this area should be heated to a temperature of $+42^{\circ} \mathrm{C}$.

\section{Conflict of Interest}

None.

\section{Source of Support}

None.

\section{References}

1. Bruise. Available from: https://en.wiktionary.org/wiki/bruise\#Etymology. [Last accessed on 2020 Feb 01].

2. Bruises. Available from: https://www.webmd.com/skinproblems-and-treatments/guide/bruises-article\#1-1. [Last accessed on 2020 Feb 01].

3. Bruises: Symptoms \& Signs. Available from: https://www.medicinenet.com/easy_bruising/symptoms.htm. [Last accessed on $2020 \mathrm{Feb}$ 01].

4. Bruise. Available from: https://en.wikipedia.org/wiki/Bruise. [Last accessed on $2020 \mathrm{Feb}$ 01].

5. Razmi M., Katoch D., Dogra S. Spontaneous upper eyelid ecchymosis: A cutaneous clue to increased intracranial pressure. Journal of the American Academy of Dermatology. 2017;77(3):e65-e66.

6. What to know about bruising easily. Available from: https://www.medicalnewstoday.com/articles/325525\#when-tosee-a-doctor. [Last accessed on $2020 \mathrm{Feb} 21$ ].

7. Bruise. Available from: https://en.wikipedia.org/wiki/Bruise\#Severity. [Last accessed on 2020 Feb 26].

8. Simon L.V, Lopez R.A, King K.C. Blunt force trauma. Available from: https://www.ncbi.nlm.nih.gov/books/NBK470338/. [Last accessed on 2020 Mar 10].

9. Vester M.E.M., Bilo R.A.C., Loeve A.J., Rijn R.R., Zandwijk J.P. Modeling of inflicted head injury by shaking trauma in children: what can we learn?: Part I: A systematic review of animal models. Forensic Sci Med Pathol 2019;15(3):408-422.

10. Morley E.J, English B, Cohen D.B, Paolo W.F, Nusbaum J, Gupta $\mathrm{N}$ et al. Points \& Pearls: Blunt cardiac injury: emergency department diagnosis and management. Emerg Med Pract 2019;21(3):1-2.

11. Morley E.J, English B, Cohen D.B, Paolo W.F. Blunt cardiac injury: emergency department diagnosis and management. Emerg Med Pract 2019;21(3):1-20.

12. Urakov A.L, Urakova N.A, Chernova L.V, Fischer E.L, Nasyrov M.R. Infrared thermography forearm skin in places intradermal injections of blood or solutions of drugs before and after the appearance of the bruise. Thermology Int 2015;25(2):66-7.

13. Urakov A.L, Ammer K, Urakova N.A, Chernova L.V, Fisher E.L. Infrared thermography can discriminate the cause of skin discolourations. Thermology Int 2015;25 (4):209 - 15.

14. Urakov A.L, Urakova N.A, Lovtsova L.V, Zanozina O.V. Thermodynamic bases of diagnostics of soft tissue inflammation in the area of postinjection bruises. Med Almanac 2015;4:228 -32.

15. Urakov A, Ammer K, Urakova N, Fisher E, Chernova L. Thermal imaging improves the accuracy of forensic medical examination of living persons with bruises of soft tissues. Quantitative Infrared Thermography Council. Quebec. Univ Laval 2016:874-5.

16. Urakov A, Ammer K, Urakova N, Fisher E, Chernova L. Thermal imaging improves the accuracy of forensic medical examination of living persons with bruises of soft tissues. Quantitative Infrared Thermography 2016. ABSTRACTS 13TH Quantitative Infrared Thermography. (July 4 - 8, 2016, Gdansk, Poland) Publishing by Gdansk University of Technology, 2016:81-2.

17. Urakov A.L, Nikityuk D.B, Urakova N.A, Soikher M.I, Soikher M.G, Reshetnikov A.P et al. Types and dynamics of local skin lesions of patients in places where medication is injected. Doctor 2014;7:56-60.

18. Urakov A, Urakova N, Kasatkin A, Reshetnikov A. Infrared thermography skin at the injection site as a way of timely detection injection disease. Thermology Int 2015; 25(1):30. 
19. Kasatkin A.A, Urakov A.L, Lukoyanov I.A. Nonsteroidal antiinflammatory drugs causing local inflammation of tissue at the site of injection. $J$ Pharm Pharmacotherapeutics 2016;7(1):26-8.

20. Kasatkin A, Urakov A. Why the drug solutions may cause inflammation at the injection site. (Proceedings of 6th World Congress on Medicinal Chemistry and Drug Design. (June 07 - 08, 2017 Milan, Italy). J Med Chem: Open Access 2017;7(4):78.

21. Urakova N.A, Urakova A.L, Nikolenko V.N, Kartasheva L.F. Infrared clinical anatomy of mammary gland's additional lobe in non-pregnant young woman. Indian J Clin Anatomy Physiol 2020;7(1):127-9.

22. 20 Effective Home Remedies For Bruises. Available from: https://www.stylecraze.com/articles/effective-home-remediesfor-bruises/\#gref [Last accessed on 2020 Jan 30].

23. 10 Ways to Get Rid of Bruises. Available from: https://www.healthline.com/health/how-to-get-rid-of-bruises. pdf. [Last accessed on 2020 Jan 30].
24. Xu F, Zeng W, Mao X. The efficacy of melilotus extract in the management of postoperative ecchymosis and edema after simultaneous rhinoplasty and blepharoplasty. Aesth Plast Surg 2008; 32: 599-603.

25. Urakov A.L., Urakova N.A., Gadelshina A.A. New medicines: the bleachers of bruises, blue nails, hematomas, blood stains and bloody crusts. Aus Med J 2017;10 (11): 942-3.

26. Urakov A, Urakova N, Reshetnikov A. Oxygen alkaline dental's cleaners from tooth plaque, food debris, stains of blood and pus: A narrative review of the history of inventions. $J$ Int Soc Preven Comm Dent 2019;9(5):427-33.

27. Urakov A.L. Creation of "necessary" mixtures of baking soda, hydrogen peroxide and warm water as a strategy for modernization bleaching cleaners of ceramic. Epitöanyag $-J$ Silicate Based Composite Mater 2020;72 (1):30-5.

How to cite: Urakov A, What are bruises? Causes, Symptoms, Diagnosis, Treatment, Remedies. IP Int J Comprehensive Adv Pharmacol 2020;5(1): 